\title{
The Effect of the Flux $\mathrm{B}_{2} \mathrm{O}_{3}$ and the Role of Ion $\mathrm{RE}^{3+}$ in $\mathrm{CaAl}_{2} \mathrm{O}_{4}: \mathrm{Eu}^{2+}, \mathrm{Nd}^{3+}, \mathrm{RE}^{3+}$ Phosphor (RE: Dy, Gd, Tb)
}

\author{
Nguyen Ngoc Trac ${ }^{1,3}$, Nguyen Manh Son ${ }^{1}$, Phan Tien Dung ${ }^{2}$ and Pham Nguyen Thuy Trang ${ }^{1}$ \\ 1. Department of Physics, University of Sciences, Hue University, Hue City, Vietnam \\ 2. Vietnam Academy of Science and Technology, Cau Giay District, Hanoi, Vietnam \\ 3. Fundamental of Science Department, Hue Industrial College, Hue City, Vietnam
}

Received: December 12, 2012 / Accepted: January 08, 2013 / Published: June 25, 2013.

\begin{abstract}
The long afterglow phosphors $\mathrm{CaAl}_{2} \mathrm{O}_{4}: \mathrm{Eu}^{2+}, \mathrm{Nd}^{3+}, \mathrm{RE}^{3+}$ (RE: Dy, $\mathrm{Gd}, \mathrm{Tb}$ ) were prepared by the combustion method at $580{ }^{\circ} \mathrm{C}$ for $5 \mathrm{~min}$. In this method, the $\mathrm{B}_{2} \mathrm{O}_{3}$ oxide was used as flux. The influences of the flux $\mathrm{B}_{2} \mathrm{O}_{3}$ quantity and the role of ion $\mathrm{RE}^{3+}$ (RE: Dy, Gd, Tb) in the phosphor $\mathrm{CaAl}_{2} \mathrm{O}_{4}: \mathrm{Eu}^{2+}, \mathrm{Nd}^{3+}$ were studied systemically. The $\mathrm{X}$-ray diffraction pattern, scanning electron microscopy graphic, the photoluminescence spectra and decay time were presented. The emission spectra of phosphors had a broad band with maximum at $444 \mathrm{~nm}$ due to electron transition from the $4 \mathrm{f}^{6} 5 \mathrm{~d}^{1}$ to the $4 \mathrm{f}^{7}$ of ion $\mathrm{Eu}^{2+}$. It is showed that $\mathrm{Nd}^{3+}$ and $\mathrm{RE}^{3+}$ ions generated traps that resulted in the long persistent phosphorescence. Simultaneously, when the concentration of $\mathrm{RE}^{3+}$ ion was high, they generated also emission centers in the phosphor.
\end{abstract}

Key words: Long afterglow, phosphorescence, aluminate, combustion method.

\section{Introduction}

In recent years, rare earth doped alkaline earth aluminate phosphors have been extensively studied and used in many of applications, such as radiation dosimetry, color display, luminescent porcelain, airport, luminous paints in highway and so on [1-3]. This material has strong photoluminescence at the blue region with maximum at $444 \mathrm{~nm}$. Calcium aluminate codoped with rare earth ions $\left(\mathrm{Eu}^{2+}, \mathrm{Nd}^{3+}\right.$, $\mathrm{RE}^{3+}$ ) has well known as a long afterglow phosphor. The long afterglow and luminescent intensity can be enhanced by codoped with the third rare earth ion. In these phosphors, $\mathrm{Eu}^{2+}$ ions play a role luminescent centers and $\mathrm{RE}^{3+}$ ions act as holes [4-6]. The mechanism of persistent phosphorescence in these aluminate is considered to include the photoionization of the $\mathrm{Eu}^{2+}$ ion and a subsequent transfer of the electrons to traps formed by the lattice defects as oxide

Corresponding author: Nguyen Ngoc Trac, research field: photolminescence materials. E-mail: trac.nguyen.ngoc@gmail.com. ion vacancies and possibly also the auxiliary $\mathrm{RE}^{3+}$ ion codopants [7, 8]. It is showed that $\mathrm{Nd}^{3+}$ and $\mathrm{RE}^{3+}$ ions generated the hole traps that resulted in the long persistent phosphorescence.

In this paper, the influence of the flux $\mathrm{B}_{2} \mathrm{O}_{3}$ concentration on the crystalline structure and luminescent properties of $\mathrm{CaAl}_{2} \mathrm{O}_{4}: \mathrm{Eu}^{2+}, \mathrm{Nd}^{3+}$ phosphor were investigated. The role of $\mathrm{RE}^{3+}$ in $\mathrm{CaAl}_{2} \mathrm{O}_{4}: \mathrm{Eu}^{2+}, \mathrm{Nd}^{3+}, \mathrm{RE}^{3+}$ (RE: Dy, Gd, Tb) phosphors were also studied systemically. The materials were prepared by ure-nitrate solution combustion method.

\section{Experiments}

The powder samples with the general formula $\mathrm{CaAl}_{2} \mathrm{O}_{4}: \mathrm{Eu}^{2+}(1 \% \mathrm{~mol}), \mathrm{Nd}^{3+}(0.5 \% \mathrm{~mol})$ and $\mathrm{CaAl}_{2} \mathrm{O}_{4}: \mathrm{Eu}^{2+}$ (1\% mol), $\mathrm{Nd}^{3+}(0.5 \% \mathrm{~mol}), \mathrm{RE}^{3+}(1 \%$ $\mathrm{mol}$ ) (RE: $\mathrm{Dy}, \mathrm{Gd}, \mathrm{Tb})$ were prepared by urea-nitrate solution combustion method. Starting materials for synthesized phosphors $\mathrm{CaAl}_{2} \mathrm{O}_{4}$ codoped with rare earth ions were the mixture of $\mathrm{Ca}\left(\mathrm{NO}_{3}\right)_{2} \cdot 4 \mathrm{H}_{2} \mathrm{O}$, 
$\mathrm{Al}\left(\mathrm{NO}_{3}\right)_{3} \cdot 9 \mathrm{H}_{2} \mathrm{O}, \mathrm{Eu}_{2} \mathrm{O}_{3}, \mathrm{Nd}_{2} \mathrm{O}_{3}, \mathrm{Dy}_{2} \mathrm{O}_{3}, \mathrm{Gd}_{2} \mathrm{O}_{3}, \mathrm{~Tb}_{2} \mathrm{O}_{3}$, $\mathrm{B}_{2} \mathrm{O}_{3}$ and $\mathrm{CO}\left(\mathrm{NH}_{2}\right)_{2}$. Rare earth oxides were nitrified by dissolving into $\mathrm{HNO}_{3}$. A small quantity of $\mathrm{B}_{2} \mathrm{O}_{3}$ was added as the flux. Urea was used to supply fuel and reducing agent.

Aqueous solution containing stoichiometric amounts of nitrate metal and urea was mixed by magnetic stirrer and heated at $70{ }^{\circ} \mathrm{C}$ for $40 \mathrm{~min}$ to gel. Nextly, the gel was dried at $80{ }^{\circ} \mathrm{C}$ to dehydrate and combusted at temperatures $580{ }^{\circ} \mathrm{C}$ within $5 \mathrm{~min}$. Urea concentration was 18 times of product mole (theory 6.69). The white powder product was obtained.

The prepared products were characterized by D8-Advance-Bruker X-ray diffractometer. The scanning electron microscope (SEM) graphs were taken by FE-SEM Hitachi S4800. The photoluminescence spectra were measured by FL3-22 fluorescence spectrometer. The glow curves were analysized by Harshaw TLD-3500 equipment. The samples were irradiated by $\beta$-ray with dose $1.5 \mathrm{~Gy}$, preheated at $50{ }^{\circ} \mathrm{C}$ for $200 \mathrm{~s}$, heating rate $5{ }^{\circ} \mathrm{C} / \mathrm{s}$.

\section{Experimental Results}

3.1 The Effect of the Flux $\mathrm{B}_{2} \mathrm{O}_{3}$ Concentration on the $\mathrm{CaAl}_{2} \mathrm{O}_{4}: \mathrm{Eu}^{2+}, \mathrm{Nd}^{3+}$ Phosphor

The crystalline structure of $\mathrm{CaAl}_{2} \mathrm{O}_{4}: \mathrm{Eu}^{2+}, \mathrm{Nd}^{3+}$ with different concentration that were confirmed by $\mathrm{X}$-ray diffraction pattern (XRD), the XRD diagrams were showed in Fig. 1.

The phosphor had monocline single phase $\mathrm{CaAl}_{2} \mathrm{O}_{4}$ structure. The XRD diagrams also indicated that no impurity phase was detected in the lattice. When the concentration of the flux $\mathrm{B}_{2} \mathrm{O}_{3}$ was small, the XRD diagram exist a small quantity of $\mathrm{CaAl}_{4} \mathrm{O}_{7}$ phase.

SEM was carried out to investigate the surface morphology and crystalline sizes of the synthesized phosphor powder.

The SEM graphs taken for $\mathrm{CaAl}_{2} \mathrm{O}_{4}: \mathrm{Eu}^{2+}, \mathrm{Nd}^{3+}$ with different $\mathrm{B}_{2} \mathrm{O}_{3}$ concentrations (2\%, 3\%, $4 \%$ and $5 \%$ wt.) were showed in Figs. 2a-2d, respectively. It showed that the powder had the irregular, foamy and agglomerate particles. The foamy structure of the materials reflects the inherent nature of the combustion reaction. The surface of powder (Figs. 2a, $2 \mathrm{~b}$ and $2 \mathrm{~d}$ ) shows a lot of voids and pores which may be formed by the evolved gases during combustion reaction. However, the crystal has sharp surface morphology like single crystalline bars (Fig. 2c). It is clearly seen from these micrographs that the crystalline sizes are about several hundreds of nanomet.

The photoluminescent spectra of the phosphors $\mathrm{CaAl}_{2} \mathrm{O}_{4}: \mathrm{Eu}^{2+}, \mathrm{Nd}^{3+}$ with $\mathrm{B}_{2} \mathrm{O}_{3} x \%$ wt. $(x=2,3,4,5)$ were investigated and presented in Fig. 3. The phosphors were excited by radiation with wavelength $365 \mathrm{~nm}$. The results showed that the emission spectra of the phosphors had a same broad band with maximum intensity at $444 \mathrm{~nm}$ that characterized the transition of electronic configuration from $4 f^{6} 5 d^{1}$ to $4 \mathrm{f}^{7}$ of $\mathrm{Eu}^{2+}$ ion. The photoluminescent intensity of $\mathrm{CaAl}_{2} \mathrm{O}_{4}: \mathrm{Eu}^{2+}, \mathrm{Nd}^{3+}$ phosphors depend on the concentration of $\mathrm{B}_{2} \mathrm{O}_{3}$ and the luminescent intensity is optimal with $\mathrm{B}_{2} \mathrm{O}_{3} 4 \%$ wt. Simultaneously, $\mathrm{Eu}^{2+}$ ions play a role emission centers and $\mathrm{Nd}^{3+}$ ions act as hole traps that trap and release charges to form the phosphorescence of materials.

Fig. 4 shows the phosphorescent decay time of the $\mathrm{CaAl}_{2} \mathrm{O}_{4}: \mathrm{Eu}^{2+}, \mathrm{Nd}^{3+}$ phosphors with different $\mathrm{B}_{2} \mathrm{O}_{3}$ concentrations. The phosphors were excited by radiation with wavelength $365 \mathrm{~nm}$ for $1 \mathrm{~min}$. The results indicated that the phosphor of $\mathrm{CaAl}_{2} \mathrm{O}_{4}: \mathrm{Eu}^{2+}$, $\mathrm{Nd}^{3+}$ with $\mathrm{B}_{2} \mathrm{O}_{3} 4 \%$ wt. has long afterglow and high

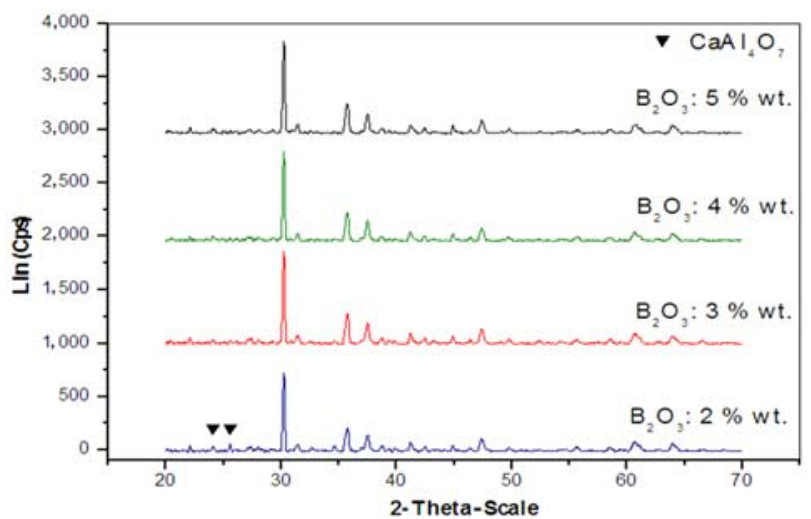

Fig. 1 XRD of $\mathrm{CaAl}_{2} \mathrm{O}_{4}: \mathrm{Eu}^{2+}, \mathrm{Nd}^{3+}$ with different concentration of $\mathrm{B}_{2} \mathrm{O}_{3}$. 
(RE: Dy, Gd, Tb)

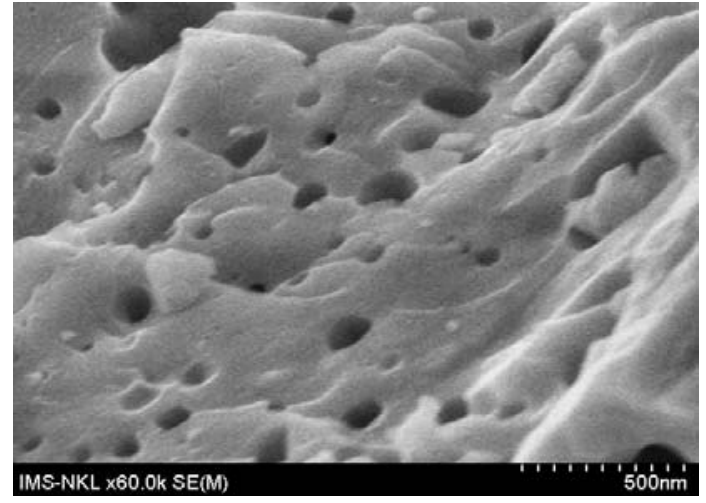

(a)

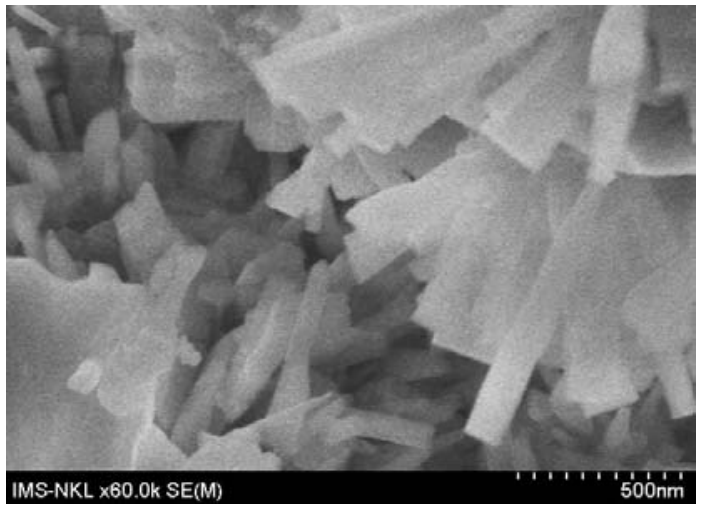

(c)

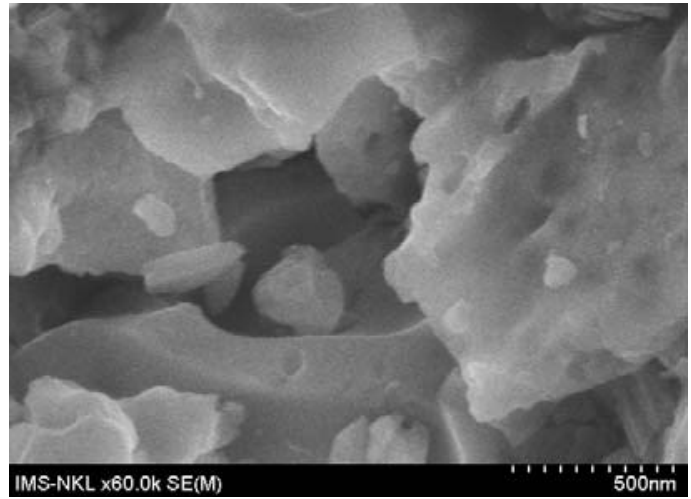

(b)

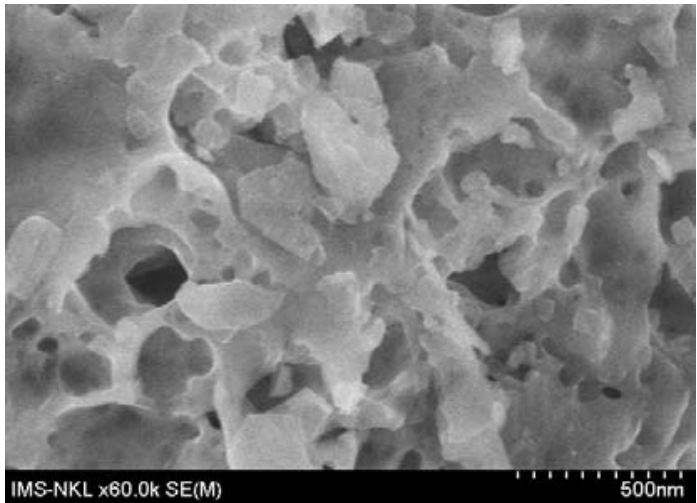

(d)

Fig. 2 SEM graphs of $\mathrm{CaAl}_{2} \mathrm{O}_{4}: \mathrm{Eu}^{2+}$, $\mathrm{Nd}^{3+}$ with different $\mathrm{B}_{2} \mathrm{O}_{3}(x \%$ wt.) concentrations: (a) $x=0.2$, (b) $x=0.3$, (c) $x=0.4$ and (d) $x=0.5$.

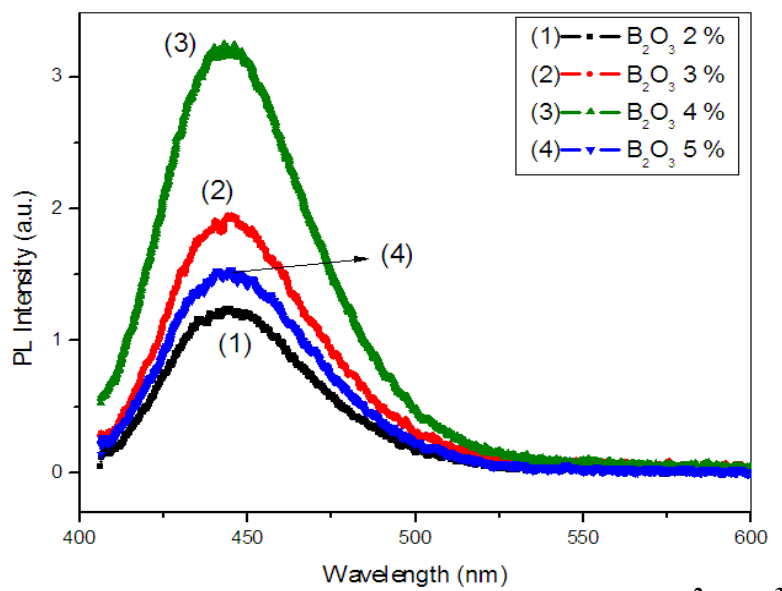

Fig. 3 Photoluminescence spectra of $\mathrm{CaAl}_{2} \mathrm{O}_{4}: \mathrm{Eu}^{2+}, \mathrm{Nd}^{3+}$ phosphors with $\mathrm{B}_{2} \mathrm{O}_{3}(\mathrm{x} \%$ wt.) $x=2,3,4,5$.

brightness. And so, their thermoluminescent properties were studied. The glow curves of the phosphors were recorded in the Fig. 5. The thermoluminescent intensity of $\mathrm{CaAl}_{2} \mathrm{O}_{4}: \mathrm{Eu}^{2+}, \mathrm{Nd}^{3+}$ the phosphor with $\mathrm{B}_{2} \mathrm{O}_{3} 4 \%$ wt. is the strongest. It is indicated that the activator centers and the density of

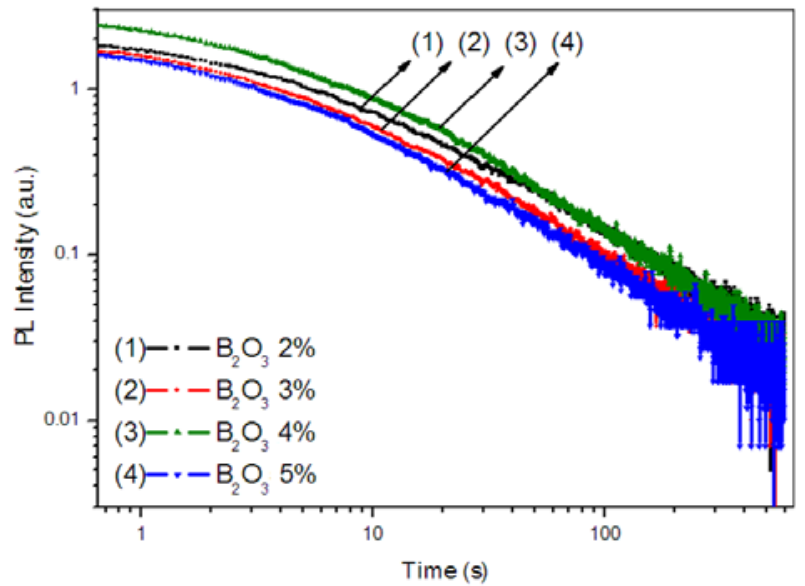

Fig. 4 Decay time of $\mathrm{CaAl}_{2} \mathrm{O}_{4}: \mathrm{Eu}^{2+}, \mathrm{Nd}^{3+}$ phosphors with different $\mathrm{B}_{2} \mathrm{O}_{3}$ concentrations.

traps produced were more suitable than that of the other concentrations of $\mathrm{B}_{2} \mathrm{O}_{3}$.

3.2 The Effect of $\mathrm{RE}^{3+}$ Ions in $\mathrm{CaAl}_{2} \mathrm{O}_{4}: \mathrm{Eu}^{2+}, \mathrm{Nd}^{3+}, \mathrm{RE}^{3+}$

Fig. 6 shows the photoluminescent spectra of the phosphors $\mathrm{CaAl}_{2} \mathrm{O}_{4}$ : $\mathrm{Eu}^{2+}, \mathrm{Nd}^{3+}, \mathrm{RE}^{3+}$. The radiation 


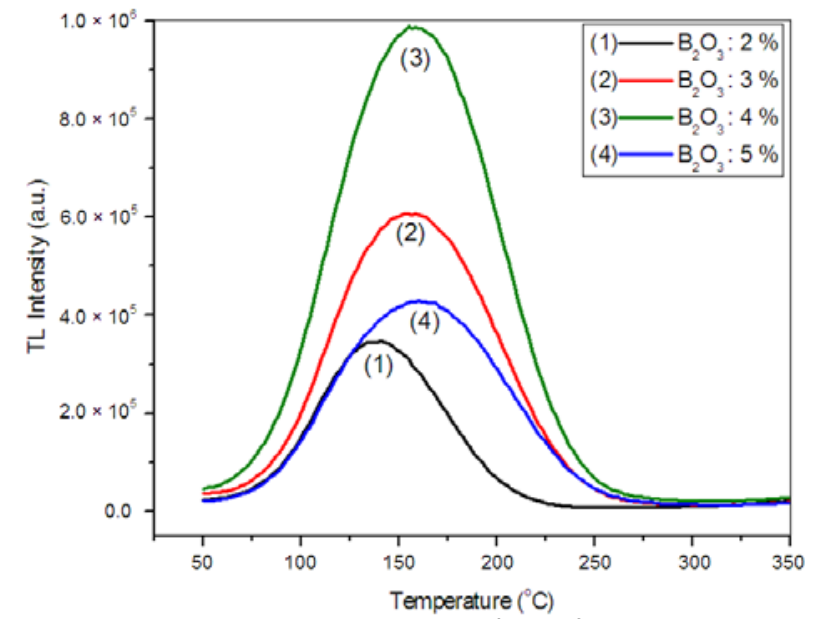

Fig. 5 Glow curve of $\mathrm{CaAl}_{2} \mathrm{O}_{4}: \mathrm{Eu}^{2+}, \mathrm{Nd}^{3+}$ phosphors with different $\mathrm{B}_{2} \mathrm{O}_{3}$ concentrations.

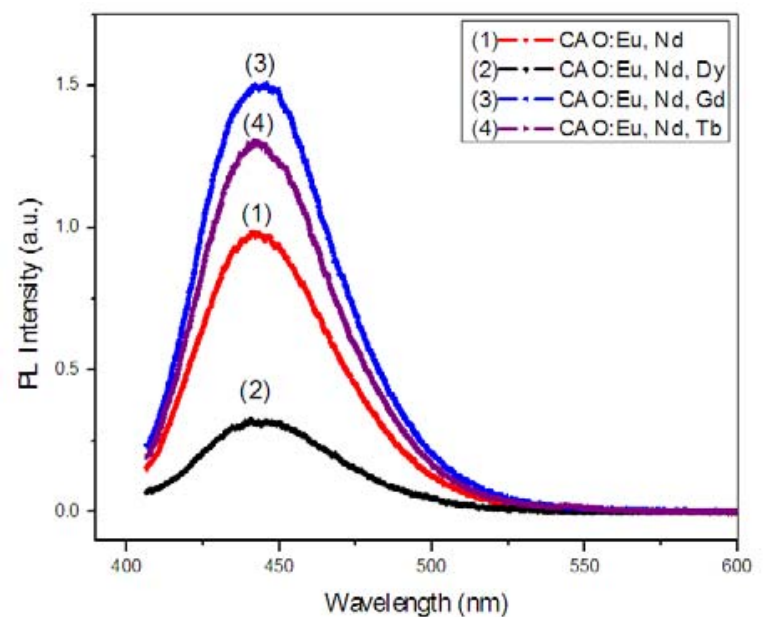

Fig. 6 Photoluminescence spectra of $\mathrm{CaAl}_{2} \mathrm{O}_{4}: \mathrm{Eu}^{2+}, \mathrm{Nd}^{3+}$, $\mathrm{RE}^{3+}$ (RE: Dy, Gd, Tb).

with wavelength $365 \mathrm{~nm}$ was used to excited the phosphors. The results showed that the emission spectra of the phosphors had a same broad band with maximum intensity at $444 \mathrm{~nm}$ that characterized the electronic transition of $\mathrm{Eu}^{2+}$ ion. The emissions of $\mathrm{Eu}^{3+}, \mathrm{Nd}^{3+}, \mathrm{Dy}^{3+}, \mathrm{Gd}^{3+}$ and $\mathrm{Tb}^{3+}$ ions were not observed in the spectra. In the $\mathrm{CaAl}_{2} \mathrm{O}_{4}: \mathrm{Eu}^{2+}, \mathrm{Nd}^{3+}$ codoped with $\mathrm{RE}^{3+}$ phosphors, the photoluminescent intensity of $\mathrm{CaAl}_{2} \mathrm{O}_{4}: \mathrm{Eu}^{2+}, \mathrm{Nd}^{3+}$ codoped with $\mathrm{Gd}^{3+}$ or $\mathrm{Tb}^{3+}$ are stronger than the uncodoped phosphor. Whereas, the photoluminescent intensity of the phosphor $\mathrm{CaAl}_{2} \mathrm{O}_{4}$ : $\mathrm{Eu}^{2+}, \mathrm{Nd}^{3+}$ codoped with $\mathrm{Dy}^{3+}$ is lower. These results related to their phosphorescent characteristic.

The decay time of $\mathrm{CaAl}_{2} \mathrm{O}_{4}: \mathrm{Eu}^{2+}, \mathrm{Nd}^{3+}, \mathrm{RE}^{3+}$ phosphors were presented in Fig. 7. It is showed that the brightness of $\mathrm{CaAl}_{2} \mathrm{O}_{4}: \mathrm{Eu}^{2+}, \mathrm{Nd}^{3+}$ codoped with $\mathrm{Gd}^{3+}$ or $\mathrm{Tb}^{3+}$ are higher than the uncodoped phosphor. Otherwise, brightness of $\mathrm{CaAl}_{2} \mathrm{O}_{4}: \mathrm{Eu}^{2+}, \mathrm{Nd}^{3+}$ codoped with $\mathrm{Dy}^{3+}$ is lower.

The lifetime of phosphors were calculated from fitting experimental decay time with the combination of three exponential functions. The results showed in Table 1. It is indicated that the lifetime of phosphors are approximate to each other.

The thermoluminescent properties of the phosphors were also investigated. The results were showed in Fig. 8. The peak of glow curves were around from 50 ${ }^{\circ} \mathrm{C}$ to $270{ }^{\circ} \mathrm{C}$. By preheated at $50{ }^{\circ} \mathrm{C}$ within $200 \mathrm{~s}$, the glow curves had symmetric single peaks. Beside, the thermoluminescent of $\mathrm{CaAl}_{2} \mathrm{O}_{4}: \mathrm{Eu}^{2+}$, $\mathrm{Nd}^{3+}, \mathrm{Dy}^{3+}$ was quite low and consisted of two peaks that located at $148{ }^{\circ} \mathrm{C}$ and $201{ }^{\circ} \mathrm{C}$. That is the reason of quite low phosphorescent property. The peak shape method (R. Chen method) [9] was applied to calculate the activation energy that the results showed in Table 2 .

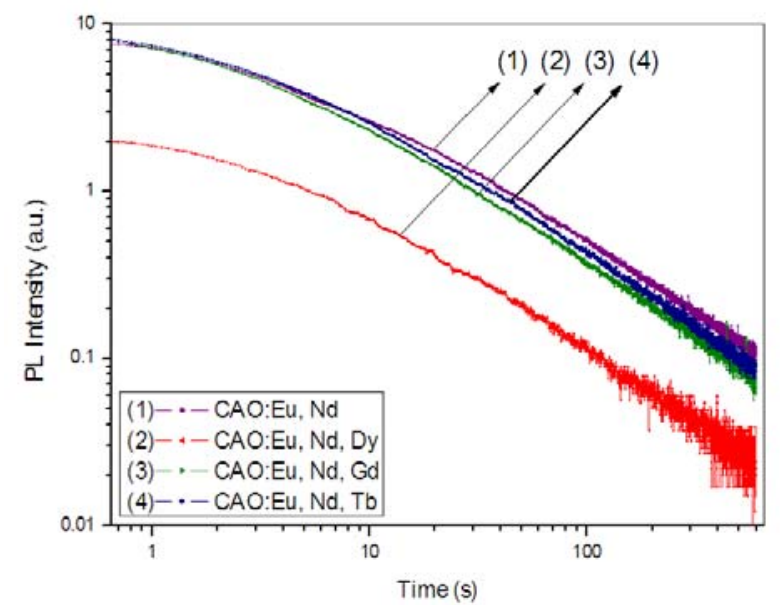

Fig. 7 Decay time of $\mathrm{CaAl}_{2} \mathrm{O}_{4}: \mathrm{Eu}^{2+}, \mathrm{Nd}^{3+}$ and $\mathrm{RE}^{3+}$ (RE: Dy, Gd, Tb).

Table 1 The values of the lifetime of $\mathrm{CaAl}_{2} \mathrm{O}_{4}: \mathrm{Eu}^{2+}, \mathrm{Nd}^{3+}$ and $\mathrm{RE}^{3+}$ phosphors.

\begin{tabular}{llll}
\hline Sample & $\tau_{1}(\mathrm{~s})$ & $\tau_{2}(\mathrm{~s})$ & $\tau_{3}(\mathrm{~s})$ \\
\hline $\mathrm{CaAl}_{2} \mathrm{O}_{4}: \mathrm{Eu}^{2+}, \mathrm{Nd}^{3+}$ & 17.3 & 2.4 & 114 \\
$\mathrm{CaAl}_{2} \mathrm{O}_{4}: \mathrm{Eu}^{2+}, \mathrm{Nd}^{3+}, \mathrm{Dy}^{3+}$ & 18.3 & 3.5 & 112 \\
$\mathrm{CaAl}_{2} \mathrm{O}_{4}: \mathrm{Eu}^{2+}, \mathrm{Nd}^{3+}, \mathrm{Gd}^{3+}$ & 14.3 & 2.6 & 106 \\
$\mathrm{CaAl}_{2} \mathrm{O}_{4}: \mathrm{Eu}^{2+}, \mathrm{Nd}^{3+}, \mathrm{Tb}^{3+}$ & 15.7 & 2.9 & 107 \\
\hline
\end{tabular}


(RE: Dy, Gd, Tb)

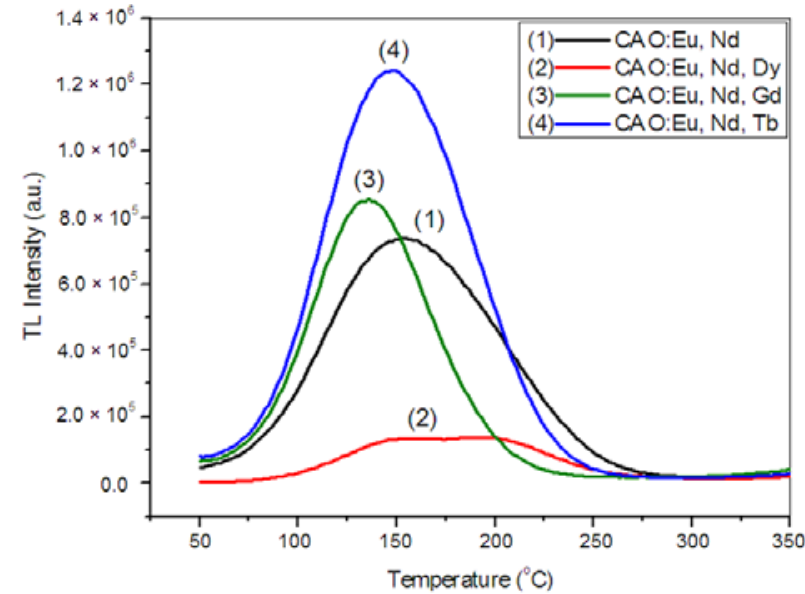

Fig. 8 Glow curve of $\mathrm{CaAl}_{2} \mathrm{O}_{4}: \mathrm{Eu}^{2+}, \mathrm{Nd}^{3+}, \mathrm{RE}^{3+}(\mathrm{RE}: \mathrm{Dy}$, Gd, Tb).

Table 2 The values of the activation energy of $\mathrm{CaAl}_{2} \mathrm{O}_{4}$ : $\mathrm{Eu}^{2+}, \mathrm{Nd}^{3+}$ and $\mathrm{RE}^{3+}$ phosphors.

\begin{tabular}{ll}
\hline Sample & $E(\mathrm{eV})$ \\
\hline $\mathrm{CaAl}_{2} \mathrm{O}_{4}: \mathrm{Eu}^{2+}, \mathrm{Nd}^{3+}$ & 0.79 \\
$\mathrm{CaAl}_{2} \mathrm{O}_{4}: \mathrm{Eu}^{2+}, \mathrm{Nd}^{3+}, \mathrm{Dy}^{3+}$ & 0.85 \\
$\mathrm{CaAl}_{2} \mathrm{O}_{4}: \mathrm{Eu}^{2+}, \mathrm{Nd}^{3+}, \mathrm{Gd}^{3+}$ & 0.84 \\
$\mathrm{CaAl}_{2} \mathrm{O}_{4}: \mathrm{Eu}^{2+}, \mathrm{Nd}^{3+}, \mathrm{Tb}^{3+}$ & 0.74 \\
\hline
\end{tabular}

\section{Conclusions}

The $\mathrm{B}_{2} \mathrm{O}_{3}$ is not only a flux but also changes emission intensity of $\mathrm{CaAl}_{2} \mathrm{O}_{4}$ : $\mathrm{Eu}^{2+}, \mathrm{Nd}^{3+}$ phosphor. The optimum concentration of the flux $\mathrm{B}_{2} \mathrm{O}_{3}$ was found to be $4 \%$ wt. for maximum luminescent intensity. The phosphors of $\mathrm{CaAl}_{2} \mathrm{O}_{4}: \mathrm{Eu}^{2+}$ codoped with $\mathrm{RE}^{3+}$ have long persistent phosphorescence. Inside, $\mathrm{CaAl}_{2} \mathrm{O}_{4}$ : $\mathrm{Eu}^{2+}, \mathrm{Nd}^{3+}$ codoped with $\mathrm{Gd}^{3+}$ or $\mathrm{Tb}^{3+}$ had long afterglow with high brightness and their photoluminescent intensity are better than $\mathrm{CaAl}_{2} \mathrm{O}_{4}$ : $\mathrm{Eu}^{2+}, \mathrm{Nd}^{3+}$. In these phosphors, $\mathrm{Eu}^{2+}$ ions play a role of activators and $\mathrm{RE}^{3+}$ ions act as hole traps.

\section{Acknowledgments}

This research has been supported by the Vietnam's
National Foundation for Science and Technology Development (NAFOSTED) with project code: 103.03-2013.67. The authors gratefully thank for this support.

\section{References}

[1] B. Zhang, C. Zhao, D. Chen, Synthesis of the long-persistence phosphor $\mathrm{CaAl}_{2} \mathrm{O}_{4}: \mathrm{Eu}^{2+}, \mathrm{Dy}^{3+}, \mathrm{Nd}^{3+}$ by combustion method and its luminescent properties, Jounal of Biological and Chemical Luminescence 25 (2010) 25-29.

[2] A. Nag, T.R.N. Kutty, Role of $\mathrm{B}_{2} \mathrm{O}_{3}$ on the phase stability and long phosphorescence of $\mathrm{SrAl}_{2} \mathrm{O}_{4}$ : Eu, Dy, Journal of Alloys and Compounds 354 (2003) 221-231.

[3] S.H. Choi, N.H. Kim, Y.H. Yun, S.C. Choi, Photoluminescence properties of $\mathrm{SrAl}_{2} \mathrm{O}_{4}$ and $\mathrm{CaAl}_{2} \mathrm{O}_{4}$ long-phosphorescent phosphors synthesized by an oxalate coprecipitation method, Journal of Ceramic Processing Research 7 (1) (2006) 62-65.

[4] H. Ryu, K.S. Bartwal, Photoluminescent spectra of $\mathrm{Nd}^{3+}$ codoped $\mathrm{CaAl}_{2} \mathrm{O}_{4}: \mathrm{Eu}^{2+}$ blue phosphor, Research Letters in Materials Science 2007 (2007) 23643.

[5] V. Singh, J.J. Zhu, M.K. Bhide, V. Natarajan, Synthesis, characterisation and luminescence investigations of $\mathrm{Eu}$ activated $\mathrm{CaAl}_{2} \mathrm{O}_{4}$ phosphor, Optical Materials 30 (2007) 446-450.

[6] X.M. Teng, W.D. Zhuang, H.Q. He, Influence of $\mathrm{La}^{3+}$ and $\mathrm{Dy}^{3+}$ on the properties of the long afterglow phosphor $\mathrm{CaAl}_{2} \mathrm{O}_{4}: \mathrm{Eu}^{2+}, \mathrm{Nd}^{3+}$, Rare Metals 27 (4) (2008) 335-339.

[7] C. Zhao, D. Chen, Synthesis of $\mathrm{CaAl}_{2} \mathrm{O}_{4}$ : Eu, Nd long persistent phosphor by combustion processes and its optical properties, Materials Letters 61 (2007) 3673-3675.

[8] Y. Lin, Z. Tang, Z. Zhang, C. Nan, Influence of co-doping different rare earth ions on the luminescence of $\mathrm{CaAl}_{2} \mathrm{O}_{4}$-based phosphors, Journal of the European Ceramic Society 23 (2003) 175-178.

[9] S.W.S. McKeever, Thernoluminescence of Solids, Cambridge University Press, Cambridge, 1985. 